\title{
BMJ Open Association between comorbid sleep apnoea-hypopnoea syndrome and prognosis of intensive care patients: a retrospective cohort study
}

\author{
Hongxia Wang (D , , Guangqiang Shao, ${ }^{2}$ Lei Rong, ${ }^{1}$ Yang $\mathrm{Ji},{ }^{1}$ Keke Zhang, ${ }^{1}$ \\ Min Liu, ${ }^{1}$ Ling $\mathrm{Ma}^{3}$
}

To cite: Wang $\mathrm{H}$, Shao $\mathrm{G}$, Rong $L$, et al. Association between comorbid sleep apnoea-hypopnoea syndrome and prognosis of intensive care patients: a retrospective cohort study. BMJ Open 2021;11:e048886. doi:10.1136/ bmjopen-2021-048886

- Prepublication history for this paper is available online. To view these files, please visit the journal online (http://dx.doi. org/10.1136/bmjopen-2021048886).

Received 10 January 2021 Accepted 20 May 2021

Check for updates

(c) Author(s) (or their employer(s)) 2021. Re-use permitted under CC BY-NC. No commercial re-use. See rights and permissions. Published by BMJ.

For numbered affiliations see end of article.

Correspondence to Guangqiang Shao, Division of Thoracic Surgery, Department of Surgery, The University of Hong Kong - Shenzhen Hospital, shenzhen, china; shaogq@hku-szh.org

\section{ABSTRACT}

Objective In this study, we investigated the association between comorbid sleep apnoea-hypopnoea syndrome (SAHS) and the prognosis of patients in an intensive care unit (ICU) to determine whether this relationship varies between different disease subgroups.

Methods We conducted a retrospective cohort study using publicly available information from the critical care database Medical Information Mart for Intensive Care III. Adults ( $\geq 18$ years of age) who attended the ICU for the first time were enrolled. Demographic information and clinical data were obtained from each patient. The primary outcome was 30-day mortality after ICU admission, and the secondary outcomes were in-hospital and ICU mortality. Multivariate logistic regression and Cox regression analyses were used to examine the associations between SAHS comorbidities and the research outcomes. Propensity score matching was used to adjust for potential confounding variables.

Results Of the 32989 patients enrolled, 1918 (5.81\%) were diagnosed with SAHS as a comorbid condition. Patients with SAHS had a significantly lower 30-day mortality rate compared with those without SAHS ( $5.27 \%$ vs $13.65 \%$, respectively; $p<0.001)$. The frequency of chronic obstructive pulmonary disease, cerebral disease, cardiovascular disease, hypertension, diabetes mellitus and renal failure was significantly different between the two groups. Patients with SAHS demonstrated significantly longer survival compared with patients without SAHS. Multivariate Cox proportional hazards regression identified a significant relationship between SAHS and mortality within 30 days (adjusted $\mathrm{HR}=0.610,95 \% \mathrm{Cl} 0.499$ to $0.747, \mathrm{p}<0.0001$ ). Conclusion SAHS as a comorbid condition decreases the risk of 30-day mortality, in-hospital mortality and ICU mortality among ICU patients.

\section{INTRODUCTION}

Sleep apnoea-hypopnoea syndrome (SAHS) is a respiratory disease in which apnoea recurs more than 30 times or the apnoea-hypopnoea index increases five times per hour during 7 hours of sleep each night. ${ }^{1}$ SAHS is one form of sleep-related breathing disorder, which encompasses obstructive sleep apnoea (OSA), ${ }^{23}$ mixed sleep apnoea, ${ }^{4}$ central sleep apnoea $(\mathrm{CSA})^{5}$
Strengths and limitations of this study

- Utilisation of a large sample size from a public data set was helpful in establishing a robust model and hierarchical analysis.

- Multivariate Cox regression identified a significant association between sleep apnoea-hypopnoea syndrome (SAHS) comorbidity and 30-day mortality.

- We performed a subgroup analysis based on different diagnoses at admission to minimise heterogeneity from the mixed intensive care unit.

- Because data on disease severity and continuous positive airway pressure (CPAP) treatment were unavailable, we did not analyse the effects of SAHS severity and CPAP treatment on mortality, both of which might be confounders.

and sleep-related hypoventilation. ${ }^{1}$ SAHS is a common comorbidity in patients with various diseases and is a risk factor for congestive heart failure, ${ }^{67}$ myocardial infarction, ${ }^{89}$ hypertension, ${ }^{10-12}$ diabetes mellitus, ${ }^{13-15}$ chronic obstructive pulmonary disease (COPD) $)^{16-19}$ and cerebral disease, ${ }^{20}$ which are also reasons for intensive care unit (ICU) admission.

OSA is associated with an increased risk of metabolic and cardiovascular comorbidities, as well as an increased risk of overall mortality. ${ }^{21-24}$ However, subjects of most previous studies were not patients in the ICU; thus, current research on the effects of comorbid SAHS on the prognosis and outcomes of critically ill patients is limited. Bolona et $a t^{25}$ showed that OSA is independently associated with lower in-hospital mortality (OR 0.408 ; $95 \%$ CI 0.298 to 0.557 ), but only disease severity was adjusted in this study. Interestingly, a recent study from Bailly et $a l^{26}$ indicated that OSA status did not affect in-hospital or ICU mortality. As SAHS is often associated with other comorbid conditions, it is important to determine if comorbid SAHS affects the prognosis and outcomes of ICU 


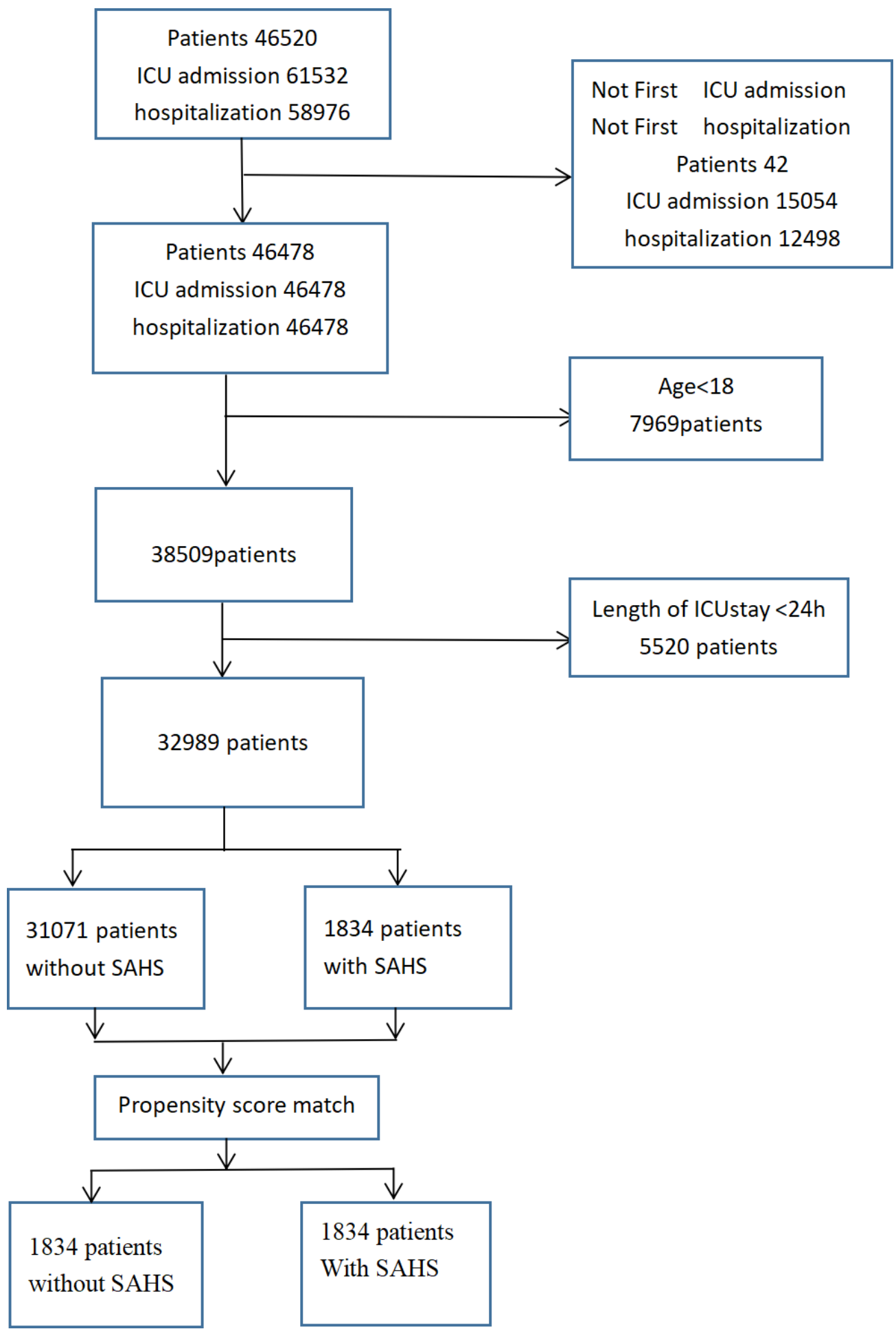

Figure 1 Flow chart depicting patients in this study. ICU, intensive care unit; SAHS, sleep apnoea-hypopnoea syndrome.

patients. In this study, we evaluated the association between comorbid SAHS and prognosis in critically ill patients.

\section{MATERIALS AND METHODS}

Patient and public involvement

Neither patients nor the public were involved in the design, conduct, reporting or dissemination of this research.

\section{Database}

In this retrospective study, we obtained data from the Medical Information Mart for Intensive Care III (MIMIC-III) database, which contains publicly available deidentified health data from more than 40000 patients admitted to the ICU of Beth Israel Deaconess Medical Center (Boston, Massachusetts, USA) from 2001 to 2012. All data analysed in this study were obtained by one of 
Table 1 Comparison of baseline characteristics and prognosis between patients in the ICU with and without SAHS

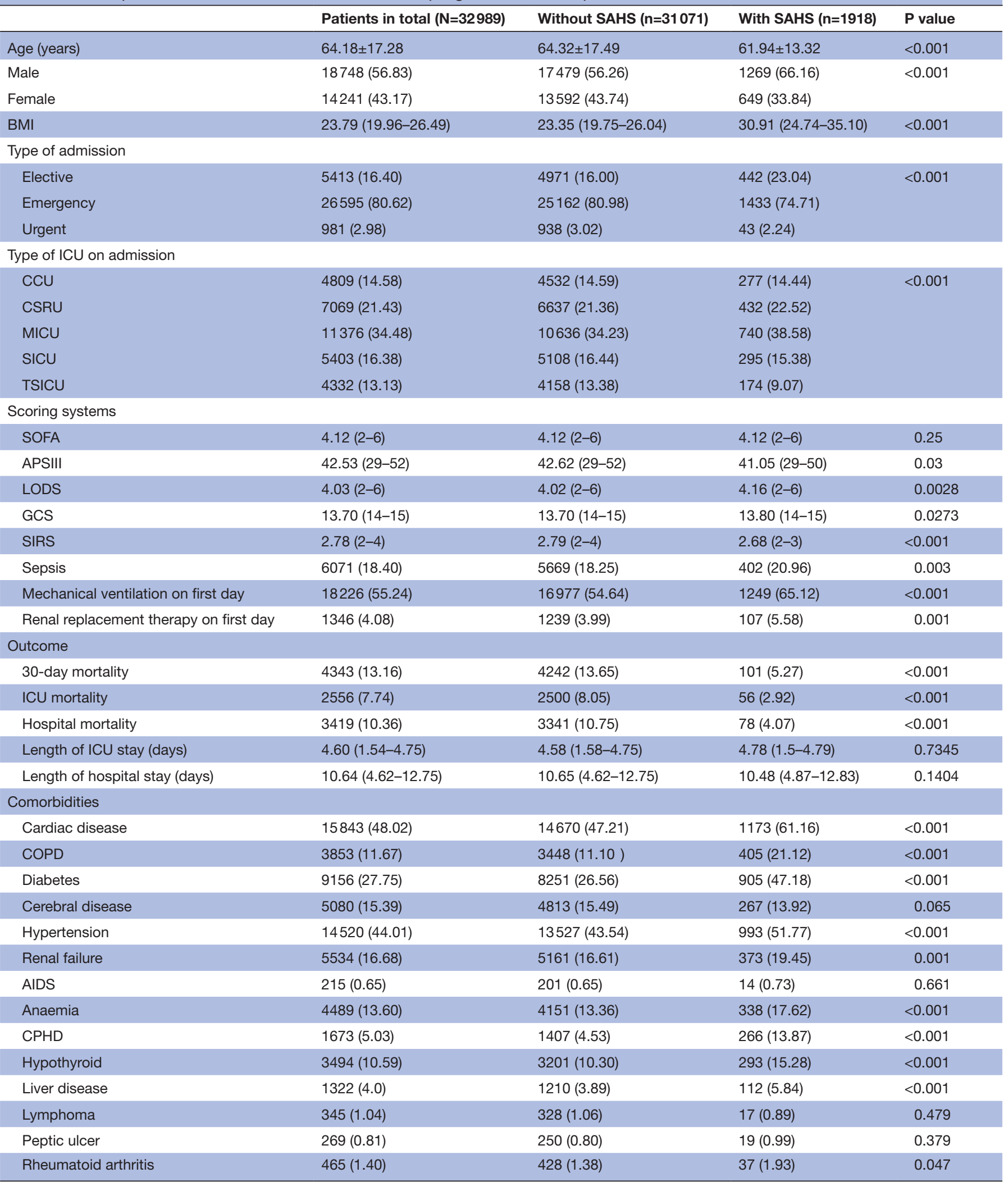

Data are expressed as mean \pm SD, median (25th-75th percentile) or $n(\%)$.

Kruskal-Wallis or $\chi^{2}$ (or Fisher's exact) test was used for comparison between groups.

*Statistical significance at $\mathrm{p}<0.05$.

APSIII, Acute Physiology Score III; BMI, body mass index; CCU, coronary care unit; COPD, chronic obstructive pulmonary disease; CPHD, chronic pulmonary heart disease; CSRU, cardiac surgery recovery unit; GCS, Glasgow Coma Scale; ICU, intensive care unit; LODS, Logistic Organ Dysfunction Score; MICU, medical intensive care unit; SAHS, sleep apnoea-hypopnoea syndrome; SICU, surgical intensive care unit; SIRS, systemic inflammatory response syndrome; SOFA,

Sequential Organ Failure Assessment; TSICU, trauma/surgical intensive care unit. 
the authors, who successfully completed the National Institutes of Health online training course (certification number: 39067458). The PostgreSQL Tools V.4.24 opensource database was used for data extraction.

\section{Study population and data extraction}

We selected patients aged $>18$ years of age when first admitted to hospital and who had an ICU length of stay of $>24$ hours. For patients with multiple hospital admissions, we analysed data from the first ICU admission only during the first hospitalisation. Detailed procedures for patient selection are presented in figure 1 .

SQL was used to extract clinical information, including age, sex, weight, height, type of ICU, reason for ICU admission, Logistic Organ Dysfunction Score (LODS), Sequential Organ Failure Assessment (SOFA) data, Glasgow Coma Scale (GCS) score, Acute Physiology Score III (APSIII) and systemic inflammatory response syndrome (SIRS). Information was also collected on other types of therapy, including mechanical ventilation on the day after admission to the ICU and renal replacement therapy. SAHS was classified using the following International Classification of Diseases, Ninth Revision, Clinical Modification (ICD-9-CM) codes: 32720, 32721, 32723, 32724, 3275, 32726, 232727 and 78057. We also extracted comorbidity information such as cardiac disease, COPD, diabetes mellitus, cerebral disease, hypertension and renal failure, which were determined by ICD-9-CM codes. In addition, to avoid the impact of missing values, we did not include laboratory measurements.

\section{Study outcomes}

The primary outcome was 30-day mortality after admission to the ICU, while the secondary outcomes were ICU mortality and in-hospital mortality. Other outcomes, such as length of ICU hospitalisation and length of overall hospital stay, were extracted for descriptive purposes only.

\section{Statistical analysis and model construction}

Data are presented as mean $\pm \mathrm{SD}$, median (25\%$75 \%$ quantile) or number (percentage). $\chi^{2}$ test, Fisher's exact test and Kruskal-Wallis test were used for group comparison. Log-rank test and Kaplan-Meier curve were used to examine survival differences between patients with SAHS and patients without comorbid SAHS. Relationships between comorbid SAHS and the primary outcome and secondary outcomes were determined with Cox proportional hazards regression and logistic regression models, respectively. Three separate analyses, which included the propensity score model, were used to adjust for potential confounding variables. Model 1 included age in years, body mass index (BMI), sex, admission type and ICU type. Model 2 included age in years, BMI, sex, admission type, ICU type, SOFA, APSIII, LODS, GCS, SIRS, sepsis, and renal replacement therapy and/or mechanical ventilation on the day following admission, as well as cardiovascular

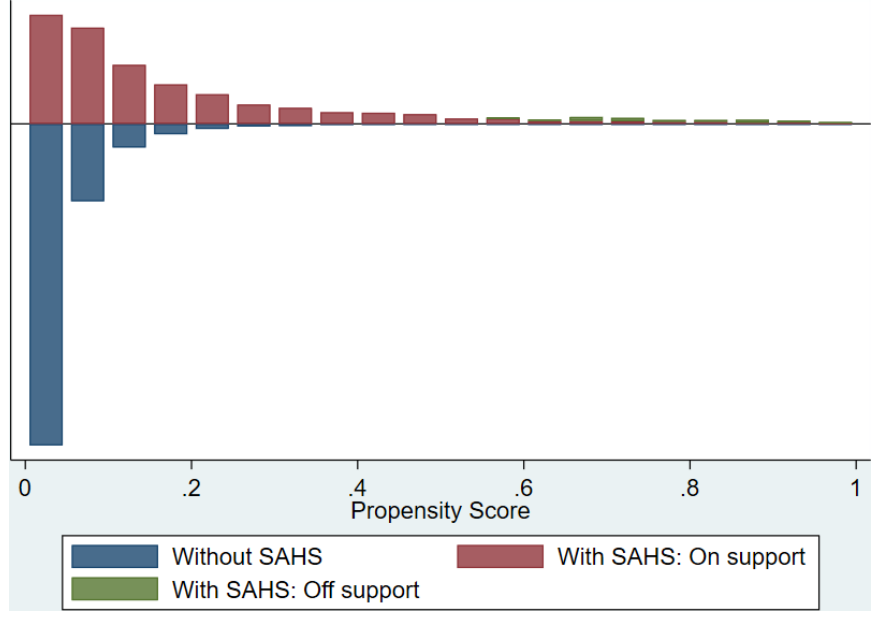

Figure 2 Propensity score matching map. SAHS, sleep apnoea-hypopnoea syndrome.

disease, COPD, cerebral disease, diabetes mellitus, hypertension, AIDS, renal failure, anaemia, chronic pulmonary heart disease, hypothyroidism, liver disease, lymphoma, peptic ulcer and rheumatoid arthritis. The propensity score model included matched sets of intervention patients and control patients who shared similar propensity scores. ${ }^{27}$ Propensity score matching is commonly used for one-to-one or matched pairs, in which pairs of intervention and control groups with similar propensity scores are formed..$^{28}$ We calculated propensity scores using the variables presented in table 1, the nearest-neighbour matching method and one-to-one matching between groups. The details are presented in figure 2. All statistical tests were two-sided and were conducted using Stata software (V.15.0). A p value $<0.05$ was considered statistically significant.

\section{RESULTS}

\section{Baseline characteristics}

Of the 32989 patients enrolled, 1918 (5.81\%) had SAHS as a comorbidity. The average age of patients was $64.18 \pm 17.28$ years. Patients without SAHS comorbidities were significantly older compared with patients with SAHS $(64.32 \pm 17.49$ years vs $61.94 \pm 13.32$ years, respectively; $\mathrm{p}<0.001)$. A greater percentage of patients with SAHS were male, and there was a difference from patients without SAHS (66.16\% vs $56.26 \%$; $<<0.001)$. In the scoring system, patients with SAHS had lower scores compared with patients without SAHS, except for SOFA and GCS scores. A higher proportion of patients in the SAHS group were diagnosed with sepsis and required mechanical ventilation and renal replacement therapy on the first day of hospitalisation compared with patients without SAHS. Compared with patients without SAHS, a higher percentage of patients with SAHS had other comorbidities. The demographic characteristics of ICU patients with and without SAHS are presented in table 1. 


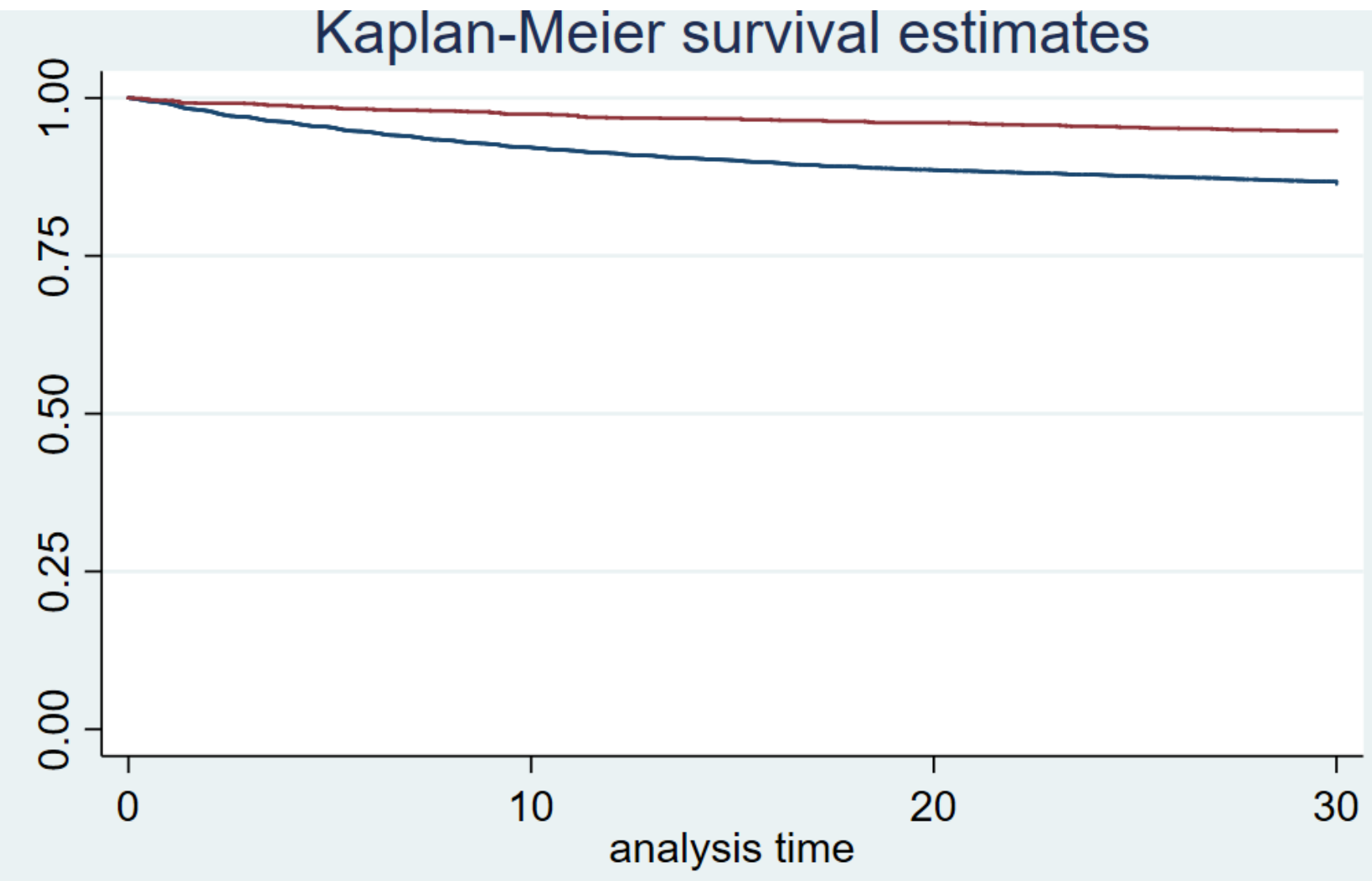

\section{Number at risk}

$\begin{array}{lccccc}\text { sleepapnea }=029625 & 28623 & 27999 & 27521 & 27224 & 26947 \\ \text { sleepapnea }=11890 & 1869 & 1855 & 1843 & 1829 & 1818\end{array}$

\section{without SAHS $=0-$ with SAHS $=1$}

Figure 3 Kaplan-Meier survival curves of patients in this study. ICU, intensive care unit; SAHS, sleep apnoea-hypopnoea syndrome.

\section{Clinical outcomes of the study and subgroups}

A total of 4343 patients $(13.16 \%)$ died within 30 days of admission to the ICU. A higher 30-day mortality rate was observed in patients without SAHS compared with those with SAHS $(13.65 \%$ vs $5.27 \%$, respectively; $\mathrm{p}<0.001)$. Similarly, ICU mortality rate $(8.05 \%$ vs $2.92 \%$, respectively; $\mathrm{p}<0.001)$ and in-hospital mortality rate $(10.75 \%$ vs $4.07 \%$, respectively; $\mathrm{p}<0.001)$ were higher in patients without SAHS compared with those with SAHS. The median length of ICU stay and hospital stay did not differ significantly between the two groups (table 1). Kaplan-Meier survival curves depict the survival of patients diagnosed with SAHS and patients without SAHS within 30 days of admission to the ICU (figure 3). The 30-day survival rate of patients with SAHS $(p<0.0001$ in a log-rank test) was significantly higher compared with patients without SAHS. Moreover, patients with SAHS in different disease subgroups, including cardiac disease, COPD, diabetes mellitus, hypertension and renal failure, were associated with lower mortality compared with patients without
SAHS (figure 4 and table 2). In the BMI subgroups, most patients with comorbid SAHS had lower 30-day mortality, ICU mortality and in-hospital mortality rates compared with patients without SAHS (table 3).

\section{Association between SAHS and clinical outcomes}

Multivariate Cox regression and logistic regression analyses indicate that patients with comorbid SAHS had a lower risk of 30-day mortality, ICU mortality and in-hospital mortality, with crude HR of 0.36 (95\% CI 0.30 to $0.44), 0.343$ (95\% CI 0.262 to 0.449$)$ and 0.351 (95\% CI 0.279 to 0.442 ), respectively. These relationships remained significant and coincident after adjustment in two models (table 4). To further explore the association between comorbid SAHS and clinical outcomes, we performed propensity score matching between the two patient groups using the variables presented in table 1 and one-to-one matching. Patients with comorbid SAHS still had a lower risk of 30-day mortality, ICU mortality and in-hospital mortality. The results of the propensity score model are presented in table 5. 

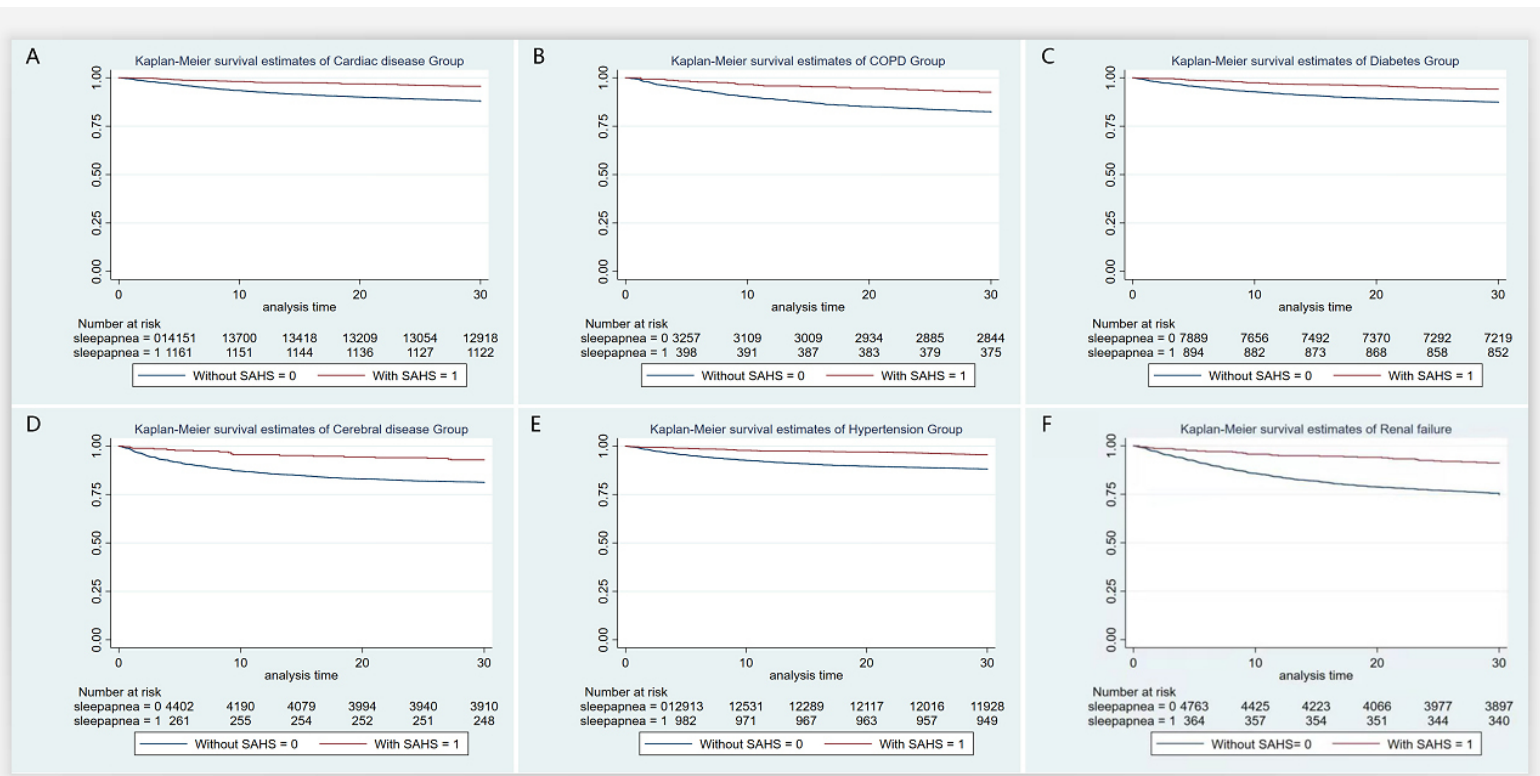

Figure 4 Kaplan-Meier survival curves for different disease subgroups: (A) cardiovascular disease, (B) COPD, (C) diabetes mellitus, (D) cerebral disease, (E) hypertension and (F) renal failure. COPD, chronic obstructive pulmonary disease; SAHS, sleep apnoea-hypopnoea syndrome.

\section{DISCUSSION}

We conducted a large retrospective cohort study using data on ICU patients from the MIMIC-III database. We found that patients with comorbid SAHS had a lower risk of 30-day mortality, ICU mortality and in-hospital mortality compared with patients without SAHS. Moreover, patients with SAHS in different disease subgroups, including cardiac disease, COPD, diabetes mellitus, cerebral disease, hypertension and renal failure, also demonstrated significantly better survival.
OSA is a common disorder in middle-aged individuals, with a prevalence of $>20 \% .{ }^{29}{ }^{30}$ According to polysomnographic assessment in ICU survivors, some studies have suggested that the prevalence of OSA is considerably high. ${ }^{31-33}$ However, there are no reliable epidemiological studies on the prevalence of SAHS in ICU patients. Only a few similar studies reported a prevalence ranging from $5.6 \%$ to $7.8 \%,{ }^{25}{ }^{26}$ which is similar to the prevalence of $5.8 \%$ observed in our study.

Table 2 Comparison of mortality between patients in different disease subgroups in the ICU with and without SAHS

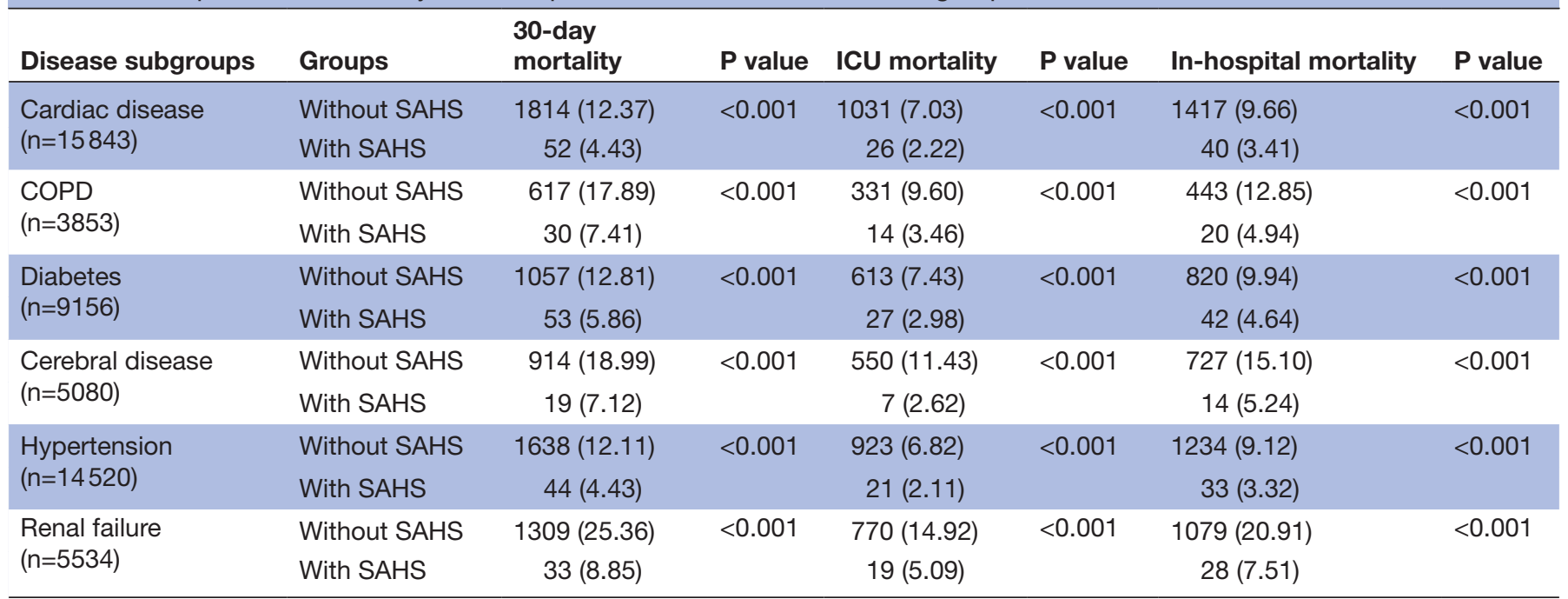

Data are expressed as $\mathrm{n}(\%)$.

$\chi^{2}$ (or Fisher's exact) test was used for comparison between groups.

${ }^{*}$ Statistical significance at $p<0.05$.

COPD, chronic obstructive pulmonary disease; ICU, intensive care unit; SAHS, sleep apnoea-hypopnoea syndrome. 
Table 3 Comparison of mortality between patients in different BMI subgroups in the ICU with and without SAHS

\begin{tabular}{|c|c|c|c|c|c|c|c|}
\hline Disease subgroups & Groups & $\begin{array}{l}\text { 30-day } \\
\text { mortality }\end{array}$ & $P$ value & ICU mortality & $P$ value & In-hospital mortality & $P$ value \\
\hline \multirow{2}{*}{$\begin{array}{l}\text { Group 1: BMI <18.5 } \\
(n=5246)\end{array}$} & Without SAHS & 1068 (20.56) & 0.058 & & 0.039 & 786 (15.13) & 0.066 \\
\hline & With SAHS & $5(9.80)$ & & $1(1.96)$ & & $3(5.88)$ & \\
\hline \multirow{2}{*}{$\begin{array}{l}\text { Group 2: } 18.5 \leq \mathrm{BMl}<23.9 \\
(\mathrm{n}=14103)\end{array}$} & Without SAHS & 1787 (12.99) & $<0.001$ & $1037(7.54)$ & 0.001 & $1404(10.21)$ & 0.001 \\
\hline & With SAHS & $22(6.30)$ & & $10(2.87)$ & & $16(4.58)$ & \\
\hline \multirow{2}{*}{$\begin{array}{l}\text { Group 3: } 24 \leq \mathrm{BMI}<28 \\
(\mathrm{n}=7554)\end{array}$} & Without SAHS & 825 (11.54) & $<0.001$ & $495(6.92)$ & $<0.001$ & $664(9.29)$ & $<0.001$ \\
\hline & With SAHS & 19 (4.69) & & 9 (2.22) & & $13(3.21)$ & \\
\hline \multirow{2}{*}{$\begin{array}{l}\text { Group 4: } 28 \leq \mathrm{BMl}<32 \\
(\mathrm{n}=3434)\end{array}$} & Without SAHS & 347 (11.41) & $<0.001$ & $243(7.99)$ & $<0.001$ & $293(9.63)$ & $<0.001$ \\
\hline & With SAHS & $12(3.06)$ & & $8(2.04)$ & & $10(2.55)$ & \\
\hline \multirow{2}{*}{$\begin{array}{l}\text { Group 5: } 32 \leq \mathrm{BMl}<40 \\
(\mathrm{n}=2092)\end{array}$} & Without SAHS & $165(10.19)$ & 0.036 & $111(6.86)$ & 0.057 & $147(9.08)$ & 0.013 \\
\hline & With SAHS & $33(6.98)$ & & $21(4.44)$ & & $26(5.50)$ & \\
\hline \multirow{2}{*}{$\begin{array}{l}\text { Group 6: BMI } \geq 40 \\
(n=560)\end{array}$} & Without SAHS & $50(16.03)$ & $<0.001$ & $40(12.82)$ & $<0.001$ & $47(15.06)$ & $<0.001$ \\
\hline & With SAHS & $10(4.03)$ & & $7(2.82)$ & & $10(4.03)$ & \\
\hline
\end{tabular}

Data are expressed as $\mathrm{n}(\%)$.

$\chi^{2}$ (or Fisher's exact) test was used for comparison between groups.

${ }^{\star}$ Statistical significance at $\mathrm{p}<0.05$.

BMI, body mass index; ICU, intensive care unit; SAHS, sleep apnoea-hypopnoea syndrome.

Compared with a study by Bolona et al, ${ }^{25}$ which used a large patient population to examine the effects of comorbid SAHS on the prognosis and outcomes of patients admitted to the ICU, there are several differences in our research. We enrolled a larger sample size, which is more advantageous for stratified analyses. We also used different methods of analysis, such as propensity score matching, to adjust for potential confounders. However, the results of both these studies are generally consistent with regard to the association between comorbid SAHS and clinical outcomes. Interestingly, a recent study from Bailly et $a l,{ }^{26}$ which used an appropriate exposed/unexposed matched design, reported the opposite conclusion. The sample size in that study was smaller, and the study did not consider the effects of sepsis, mechanical ventilation or renal replacement therapy, which may have led to poor results.

We also used propensity score matching in our study. Patients with comorbid SAHS still had a lower risk of 30-day mortality, ICU mortality and in-hospital mortality. These results indicate that SAHS may be independently associated with lower mortality rates.

Protective effects attributed to obesity in Bolona et $a l \mathrm{~s}^{25}$ research may explain these findings. The relationship between ICU prognosis and obesity has been extensively studied. Most studies found that obesity is independently associated with improved ICU outcomes, ${ }^{34-36}$ but there are some controversies. Specifically, some studies have shown no advantage or increased ICU mortality in patients with obesity. ${ }^{3738} \mathrm{It}$ is difficult to explain the results with obesity in our study because, after adjusting for BMI in different models and propensity score matching, patients without SAHS still had a lower risk of 30-day mortality, ICU mortality and in-hospital mortality compared with those with SAHS. The reason SAHS provides protection in ICU patients is unclear; however, we hypothesise that it is related to the complex pathophysiology of the disease. CSA and OSA may disrupt breathing through different physiological mechanisms and may impose qualitatively similar inflammatory burden on the cardiovascular system. The primary differences between OSA and CSA are the greater negative intrathoracic pressure and the lower average awake partial pressure of carbon dioxide (PaCO2) caused by obstructive events and greater sympathoexcitation. ${ }^{39}{ }^{40}$ With continued apnoea, OSA may transform into a pattern that resembles CSA, and if treatment improves ventricular filling pressure CSA may revert to OSA. ${ }^{41}$ Archetypical cycles of increasing and decreasing tidal volume that are characteristic of CSA, termed Cheyne-Stokes respiration, ${ }^{42-44}$ have compensatory and beneficial effects in patients with heart failure ${ }^{45}$ It is possible that the same benefits exist in critically ill patients. In addition, a landmark feature of sleep apnoea is intermittent hypoxia, which may make critically ill patients more tolerant to hypoxia and circulatory damage. The likelihood that these conjectures will be proven by research is remote. However, some researchers believe that sleep-related breathing disorders may confer underappreciated benefits that may be offset by current methods of targeted therapy. ${ }^{46}$

Interestingly, during the COVID-19 pandemic, increasing evidence suggests that OSA is an independent risk factor for severe COVID-19. ${ }^{47-49}$ A multicentre, prospective study from Peker et $a l^{77}$ showed that adults with high-risk OSA in a COVID-19 cohort had poorer clinical outcomes compared with patients with low-risk OSA, but their study focused on clinical improvement 


\begin{tabular}{|c|c|c|c|c|}
\hline Outcomes & Group & HR (or OR) & $95 \% \mathrm{Cl}$ & $P$ value \\
\hline \multicolumn{5}{|c|}{ 30-day mortality } \\
\hline \multirow[t]{2}{*}{ Crude } & Without SAHS & Ref & 0.30 to 0.44 & $<0.001$ \\
\hline & With SAHS & 0.36 & & \\
\hline \multirow[t]{2}{*}{ Model 1} & Without SAHS & Ref & 0.405 to 0.606 & $<0.001$ \\
\hline & With SAHS & 0.495 & & \\
\hline \multirow[t]{2}{*}{ Model 2} & Without SAHS & Ref & 0.499 to 0.747 & $<0.001$ \\
\hline & With SAHS & 0.610 & & \\
\hline \multicolumn{5}{|c|}{ ICU mortality } \\
\hline \multirow[t]{2}{*}{ Crude } & Without SAHS & Ref & 0.262 to 0.449 & 0.0047 \\
\hline & With SAHS & 0.343 & & \\
\hline \multirow[t]{2}{*}{ Model 1} & Without SAHS & Ref & 0.301 to 0.517 & 0.0390 \\
\hline & With SAHS & 0.349 & & \\
\hline \multirow[t]{2}{*}{ Model 2} & Without SAHS & Ref & 0.361 to 0.646 & $<0.001$ \\
\hline & With SAHS & 0.483 & & \\
\hline \multicolumn{5}{|c|}{ In-hospital mortality } \\
\hline \multirow[t]{2}{*}{ Crude } & Without SAHS & Ref & 0.279 to 0.442 & \\
\hline & With SAHS & 0.351 & & \\
\hline \multirow[t]{2}{*}{ Model 1} & Without SAHS & Ref & 0.346 to 0.554 & $<0.001$ \\
\hline & With SAHS & 0.438 & & \\
\hline \multirow[t]{2}{*}{ Model 2} & Without SAHS & Ref & 0.417 to 0.691 & $<0.001$ \\
\hline & With SAHS & 0.537 & & \\
\hline
\end{tabular}

The association between comorbid SAHS and 30-day mortality was analysed using Cox regression analysis, and in-hospital mortality and ICU mortality were analysed using logistic regression models.

Model 1 was adjusted by age, sex, BMI, type of ICU and type of admission; model 2 was adjusted by age, sex, BMI, type of ICU, type of admission, SOFA, APSIII, SIRS, LODS, GCS, sepsis, mechanical ventilation on the first day, renal replacement therapy on the first day, cardiac disease, COPD, cerebral disease, hypertension, diabetes mellitus, renal failure, AIDS, anaemia, CPHD, hypothyroidism, liver disease, lymphoma, peptic ulcer and rheumatoid arthritis.

Statistical significance at $\mathrm{p}<0.05$.

APSIII, Acute Physiology Score III; BMI, body mass index; COPD, chronic obstructive pulmonary disease; CPHD, chronic pulmonary heart disease; GCS, Glasgow Coma Scale; ICU, intensive care unit; LODS, Logistic Organ Dysfunction Score; Ref, reference; SAHS, sleep apnoea-hypopnoea syndrome; SIRS, systemic inflammatory response syndrome; SOFA, Sequential Organ Failure Assessment.

without death analysis and patients who died were excluded. A study by Strausz et $a t^{48}$ demonstrated the same trend, and the authors emphasised that OSA was associated with a higher risk of hospitalisation. Cade et $a l{ }^{49}{ }^{49}$ research revealed that patients with COVID-19 and sleep apnoea had an increased all-cause mortality rate $(11.7 \%)$ compared with control patients with sleep apnoea only $(6.0 \%)(\mathrm{p}<0.001)$, with an OR of $1.79(95 \%$ CI 1.31 to 2.45) before adjustment. However, after full adjustment, there was no significant difference in OR (1.16; $95 \%$ CI 0.8 to 1.68$)$. In addition, they found no significant difference between patients undergoing continuous positive airway pressure (CPAP) treatment in the year prior and those without CPAP treatment. Unfortunately, our research lacked CPAP treatment records and also lacked data from patients with COVID19. However, these studies suggest that OSA may play different roles in different populations; thus, further studies are needed.
There are some limitations to the present study that should be highlighted. First, a subgroup analysis based on different admission diagnoses was performed to alleviate heterogeneity from the mixed ICU. Second, due to unavailability of data on disease severity and CPAP treatment, we did not analyse the effects of SAHS severity and CPAP treatment on mortality, both of which might be confounders. These limitations led to a decline in the accuracy of our conclusions. Therefore, prospective studies, particularly studies assessing disease severity and CPAP treatment, are needed to further confirm our results.

\section{CONCLUSION}

We conclude that comorbid SAHS decreases 30-day mortality, ICU mortality and in-hospital mortality rates in ICU patients. 
Table 5 Comparison of baseline characteristics and prognosis between patients in the ICU with and without SAHS: postmatching

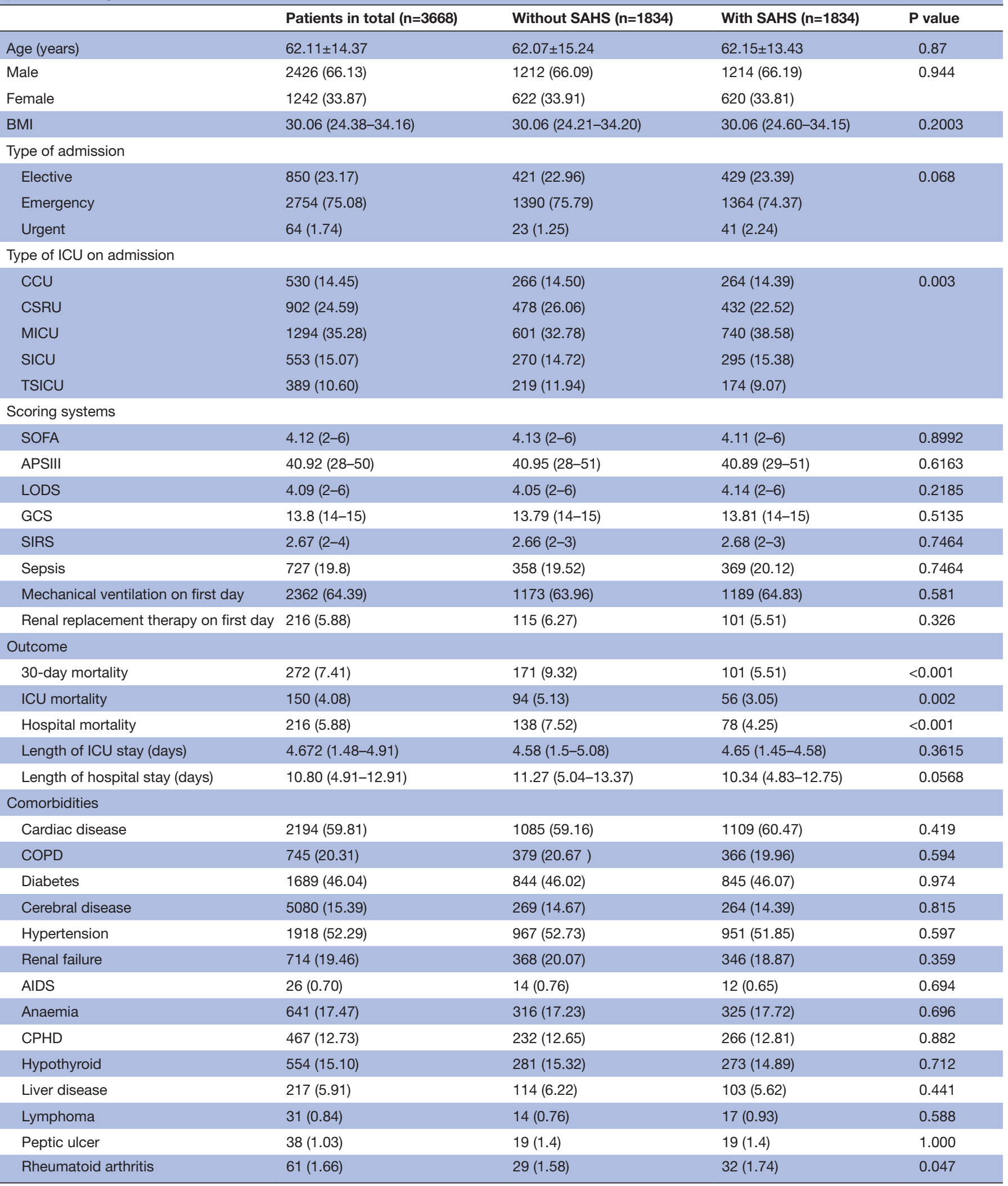

Data are expressed as mean \pm SD, median (25th-75th percentile) or $\mathrm{n}(\%)$.

Kruskal-Wallis or $\chi^{2}$ (or Fisher's exact) test was used for comparison between groups.

*Statistical significance at $\mathrm{p}<0.05$.

APSIII, Acute Physiology Score III; BMI, body mass index; CCU, coronary care unit; COPD, chronic obstructive pulmonary disease; CPHD, chronic pulmonary heart disease; CSRU, cardiac surgery recovery unit; GCS, Glasgow Coma Scale; ICU, intensive care unit; LODS, Logistic Organ Dysfunction Score; MICU, medical intensive care unit; SAHS, sleep apnoea-hypopnoea syndrome; SICU, surgical intensive care unit; SIRS, systemic inflammatory response syndrome; SOFA, Sequential Organ Failure Assessment; TSICU, trauma/surgical intensive care unit. 


\section{Author affiliations}

${ }^{1}$ Respiratory and Critical Care Medicine, The University of Hong Kong - Shenzhen Hospital, University of Hong Kong-Shenzhen Hospital, Shenzhen, China

${ }^{2}$ Division of Thoracic Surgery, Department of Surgery, The University of Hong Kong Shenzhen Hospital, Shenzhen, Shenzhen, People's Republic of China

${ }^{3}$ Otorhinolaryngology Head and Neck Surgery, The University of Hong Kong -

Shenzhen Hospital, Shenzhen, Shenzhen, People's Republic of China

Contributors HW, GS and LR designed the study. HW, GS and LM performed computation and data analysis. HW wrote the main manuscript text. YJ, KZ and ML prepared all the figures and tables. All authors contributed to discussions about the results and revised the manuscript.

Funding This study was financially supported by Sanming Project of Medicine in Shenzhen, 'the Integrated Airways Disease team led by Professor Kian Fan Chung from Imperial College London' (grant/award number: SZSM201612096).

Competing interests None declared.

Patient and public involvement Patients and/or the public were not involved in the design, or conduct, or reporting, or dissemination plans of this research.

Patient consent for publication Not required.

Ethics approval This study was exempt from institutional review board review and informed consent from patients was not required because we used data from an anonymous public database and hence there is no need for ethical approval.

Provenance and peer review Not commissioned; externally peer reviewed.

Data availability statement Data are available in a public, open-access repository from the critical care database, MIMIC-III.

Open access This is an open access article distributed in accordance with the Creative Commons Attribution Non Commercial (CC BY-NC 4.0) license, which permits others to distribute, remix, adapt, build upon this work non-commercially, and license their derivative works on different terms, provided the original work is properly cited, appropriate credit is given, any changes made indicated, and the use is non-commercial. See: http://creativecommons.org/licenses/by-nc/4.0/.

ORCID iD

Hongxia Wang http://orcid.org/0000-0001-8779-1201

\section{REFERENCES}

1 Berry RB, Budhiraja R, Gottlieb DJ, et al. Rules for scoring respiratory events in sleep: update of the 2007 AASM manual for the scoring of sleep and associated events. deliberations of the sleep apnea definitions Task force of the American Academy of sleep medicine. $J$ Clin Sleep Med 2012;8:597-619.

2 Park JG, Ramar K, Olson EJ. Updates on definition, consequences, and management of obstructive sleep apnea. Mayo Clin Proc 2011;86:549-55.

3 Punjabi NM. The epidemiology of adult obstructive sleep apnea. Proc Am Thorac Soc 2008;5:136-43.

4 Palman AD. Kompleksnoe apnoé sna [Complex sleep apnea syndrome]. Zh Nevrol Psikhiatr Im S S Korsakova 2017;117:60-6.

5 Javaheri S, Dempsey JA. Central sleep apnea. Compr Physiol 2013;3:141-63.

6 Gottlieb DJ, Yenokyan G, Newman AB, et al. Prospective study of obstructive sleep apnea and incident coronary heart disease and heart failure: the sleep heart health study. Circulation 2010;122:352-60.

7 Javaheri S, Javaheri S, Javaheri A. Sleep apnea, heart failure, and pulmonary hypertension. Curr Heart Fail Rep 2013;10:315-20.

8 Vozoris NT. Sleep apnea-plus: prevalence, risk factors, and association with cardiovascular diseases using United States population-level data. Sleep Med 2012;13:637-44.

9 Oh MS, Bliwise DL, Smith AL, et al. Obstructive sleep apnea, sleep symptoms, and their association with cardiovascular disease. Laryngoscope 2020;130:1595-602.

10 Bleckwenn M, Linnenkamp D, et,al. Prävalenz der Schlafapnoe bei Patienten mit der Erstdiagnose eines Bluthochdrucks [Prevalence of sleep apnea in patients with first diagnosis of hypertension]. MMW Fortschr Med 2019;161:3-6.

11 Ren R, Covassin N, Zhang Y, et al. Interaction between slow wave sleep and obstructive sleep apnea in prevalent hypertension. Hypertension 2020;75:516-23.
12 Han B, Chen WZ, Li YC, et al. Sleep and hypertension. Sleep Breath 2020;24:351-6.

13 Khalil M, Power N, Graham E, et al. The association between sleep and diabetes outcomes - A systematic review. Diabetes Res Clin Pract 2020;161:108035.

14 Qie R, Zhang D, Liu L, L,et,al L, et al. Obstructive sleep apnea and risk of type 2 diabetes mellitus: a systematic review and dose-response meta-analysis of cohort studies. J Diabetes 2020;12:455-64.

15 Goyal A, Gupta P. Obstructive sleep apnoea in patients with type 2 diabetes mellitus. Diabetes Res Clin Pract 2020;160:107777.

16 Jen R, Li Y, Owens RL, et al. Sleep in chronic obstructive pulmonary disease: evidence gaps and challenges. Can Respir J 2016;2016:1-5.

17 Zhao YY, Blackwell T, Ensrud KE, et al. Sleep apnea and obstructive airway disease in older men: outcomes of sleep disorders in older men study. Sleep 2016;39:1343-51.

18 Soler X, Gaio E, Powell FL, et al. High prevalence of obstructive sleep apnea in patients with moderate to severe chronic obstructive pulmonary disease. Ann Am Thorac Soc 2015;12:1219-25.

19 Mieczkowski B, Ezzie ME. Update on obstructive sleep apnea and its relation to COPD. Int J Chron Obstruct Pulmon Dis 2014;9:349-62.

20 Chokesuwattanaskul A, Lertjitbanjong $\mathrm{P}$, Thongprayoon $\mathrm{C}$, et al. Impact of obstructive sleep apnea on silent cerebral small vessel disease: a systematic review and meta-analysis. Sleep Med 2020;68:80-8.

21 Baguet J-P, Barone-Rochette G, Tamisier R, et al. Mechanisms of cardiac dysfunction in obstructive sleep apnea. Nat Rev Cardiol 2012:9:679-88

22 Alexopoulou C, Bolaki M, Akoumianaki E, et al. Sleep quality in survivors of critical illness. Sleep Breath 2019;23:463-71.

23 Javaheri S, Barbe F, Campos-Rodriguez F, et al. Sleep apnea: types, mechanisms, and clinical cardiovascular consequences. J Am Coll Cardiol 2017;69:841-58.

24 Fonseca MIP, Pereira T, Caseiro P. Death and disability in patients with sleep apnea--a meta-analysis. Arq Bras Cardiol 2015;104:58-66

25 Bolona E, Hahn PY, Afessa B. Intensive care unit and hospital mortality in patients with obstructive sleep apnea. $J$ Crit Care 2015;30:178-80.

26 Bailly S, Galerneau L-M, Ruckly S, et al. Impact of obstructive sleep apnea on the obesity paradox in critically ill patients. J Crit Care 2020;56:120-4.

27 Rosenbaum PR, Rubin DB. Reducing bias in observational studies using subclassification on the propensity score. J Am Stat Assoc 1984;79:516-24.

28 Austin PC. An introduction to propensity score methods for reducing the effects of confounding in observational studies. Multivariate Behav Res 2011:46:399-424.

29 Heinzer R, Vat S, Marques-Vidal P, et al. Prevalence of sleepdisordered breathing in the general population: the HypnoLaus study. Lancet Respir Med 2015;3:310-8.

30 Peppard PE, Young T, Barnet JH, et al. Increased prevalence of sleep-disordered breathing in adults. Am J Epidemiol 2013;177:1006-14.

31 Thille AW, Córdoba-Izquierdo A, Maitre B, et al. High prevalence of sleep apnea syndrome in patients admitted to ICU for acute hypercapnic respiratory failure: a preliminary study. Intensive Care Med 2018;44:267-9.

32 Adler D, Pépin J-L, Dupuis-Lozeron E, et al. Comorbidities and subgroups of patients surviving severe acute hypercapnic respiratory failure in the intensive care unit. Am J Respir Crit Care Med 2017;196:200-7.

33 Alexopoulou C, Bolaki M, Akoumianaki E, et al. Sleep quality in survivors of critical illness. Sleep Breath 2019;23:463-71.

34 Pépin JL, Timsit JF, Tamisier R, et al. Prevention and care of respiratory failure in obese patients. Lancet Respir Med 2016;4:407-18.

35 Garrouste-Orgeas M, Troché G, Azoulay E, et al. Body mass index an additional prognostic factor in ICU patients. Intensive Care Med 2004;30:437-43.

36 Tremblay A, Bandi V. Impact of body mass index on outcomes following critical care. Chest 2003;123:1202-7.

37 Ray DE, Matchett SC, Baker K, et al. The effect of body mass index on patient outcomes in a medical ICU. Chest 2005;127:2125-31.

38 Dube DS. Influence of overweight on ICU mortality: a prospective study. Chest 2005;127:683.

39 Sin DD, Fitzgerald F, Parker JD, et al. Risk factors for central and obstructive sleep apnea in 450 men and women with congestive heart failure. Am J Respir Crit Care Med 1999;160:1101-6.

40 Mansfield D, Kaye DM, Brunner La Rocca H, et al. Raised sympathetic nerve activity in heart failure and central sleep apnea is due to heart failure severity. Circulation 2003;107:1396-400. 
41 Lyons OD, Bradley TD. Heart failure and sleep apnea. Can J Cardiol 2015;31:898-908.

42 Bradley TD, Logan AG, Kimoff RJ, et al. Continuous positive airway pressure for central sleep apnea and heart failure. $N$ Engl J Med 2005;353:2025-33.

43 Cowie MR, Woehrle H, Wegscheider K, et al. Adaptive ServoVentilation for central sleep apnea in systolic heart failure. $N$ Engl $J$ Med 2015;373:1095-105.

44 Emdin M, Mirizzi G, Giannoni A, et al. Prognostic Significance of Central Apneas Throughout a 24-Hour Period in Patients With Heart Failure. J Am Coll Cardiol 2017;70:1351-64.

45 Naughton MT. Cheyne-Stokes respiration: friend or foe? Thorax 2012;67:357-60.
46 Floras JS, Apnea S. Sleep apnea and cardiovascular disease: an enigmatic risk factor. Circ Res 2018;122:1741-64.

47 Peker Y, Celik Y, Arbatli S, et al. Effect of high-risk obstructive sleep apnea on clinical outcomes in adults with coronavirus disease 2019: a multicenter, prospective, observational cohort study. Ann Am Thorac Soc 2021. doi:10.1513/AnnalsATS.202011-1409OC. [Epub ahead of print: 17 Feb 2021].

48 Strausz S, Kiiskinen T, Broberg M, et al. Sleep apnoea is a risk factor for severe COVID-19. BMJ Open Respir Res 2021;8:e000845.

49 Cade BE, Dashti HS, Hassan SM, et al. Sleep apnea and COVID-19 mortality and hospitalization. Am J Respir Crit Care Med 2020;202:1462-4. 